\title{
Hong Kong JULAC Common Library Card
}

\author{
Venia Y. M. Mak, Diana L. H. Chan, and K. T. Lam \\ Hong Kong University of Science and Technology Library \\ Y. O. Li \\ Hong Kong Baptist University Library
}

\section{Structured Abstract}

\section{Purpose}

This paper describes a collaborative project on issuing a library card for common access among all eight higher education libraries in Hong Kong.

\section{Design/methodology/approach}

The project was undertaken by two committees and a task force of cross-institutional membership. The new common library card adopts the "patron-record-on-demand model", reducing the risks involved in patron data transfer across institutions. Historical narrative combined with usage analysis from the launch date of the project was outlined.

\section{Findings}

The new common library cards were well received. About $63 \%$ of old cards were replaced by new ones. New applications jumped $43 \%$ while physical access to host libraries increased by $8 \%$ during the reporting period.

\section{Originality/value}

This paper describes in detail the processes of developing a common barcode, an automated card registration system and the issuing of the common library cards. Libraries pursuing an efficient way of sharing library resources will be inspired by the level of collaboration involved in this project.

\section{Keywords}

Access services, Collaboration, Library card, Hong Kong, Personal Data Privacy, University libraries

\section{Article Classification \\ Case study}




\section{Hong Kong JULAC Common Library Card}

\section{About JULAC}

The Joint University Librarians Advisory Committee (JULAC, http://www.julac.org/) was established in Hong Kong in 1967. It is a forum to discuss, coordinate and collaborate on library information resources and services among the eight University Grants Committee-funded (UGCfunded) libraries in Hong Kong. As of June 2014, JULAC had eight member libraries with a total of 91,423 students and over 11 million volumes of print monographs [Table 1]. JULAC has an ingrained culture of collaboration, despite the fact that member libraries have varying user and collection size. Members collaborate for mutual benefits, work efficiency and cost effectiveness. Various cooperative activities such as Consortium for All Library Resources Acquisitions (Consortiall), Hong Kong Chinese Authority Name Project (HKCAN), Hong Kong Monograph Acquisitions Consortium (HKMAC), Rapid Inter-Library Loans and Hong Kong Academic Library Link (HKALL) are supported by different JULAC committees and a full-time project manager whose salary is being shared by the member libraries (Perushek and Douglas, 2014).

\begin{tabular}{|l|r|r|}
\hline JULAC Member Libraries & \multicolumn{1}{|l|}{$\begin{array}{l}\text { Student } \\
\text { Enrolment }\end{array}$} & $\begin{array}{l}\text { Print } \\
\text { Monographs }^{2}\end{array}$ \\
\hline City University of Hong Kong & 12,922 & $1,259,638$ \\
\hline The Chinese University of Hong Kong & 18,228 & $2,587,498$ \\
\hline Hong Kong Baptist University & 6,673 & $1,179,152$ \\
\hline The Hong Kong Institute of Education & 6,141 & 823,205 \\
\hline The Hong Kong Polytechnic University & 17,074 & $1,283,862$ \\
\hline Hong Kong University of Science and Technology & 10,128 & 716,814 \\
\hline Lingnan University & 2,644 & 514,798 \\
\hline University of Hong Kong & 17,613 & $2,990,381$ \\
\hline Total & $\mathbf{9 1 , 4 2 3}$ & $\mathbf{1 1 , 3 5 5 , 3 4 8}$ \\
\hline
\end{tabular}

[Table 1] Information of JULAC Member Libraries

\footnotetext{
${ }^{1}$ Student Enrolment (Full-time Equivalent) of UGC-funded Programmes by Institution in 2013/14, available at http://cdcf.ugc.edu.hk/cdcf/searchStatSiteReport.do, (accessed April 21, 2015)

${ }^{2}$ Number of print monographs of eight institutions in 2013/14, available at http://www.julac.org, (accessed April 21, 2015)
} 


\section{About JULAC Common Library Card}

HKALL and JULAC Common Library Card (JULAC Card) are two major projects supported by JULAC Access Service Committee (JASC) to facilitate reciprocal access to library resources among all member libraries. HKALL is an unmediated user initiated consortial circulation service. It allows over 90,000 students and all eligible staff of the eight libraries to search an aggregate collection of over 11 million volumes of print monographs. Users can make direct requests on these materials, which will be delivered to their home libraries for checkouts (Sidorko, 2006). Non-print materials such as microforms, databases, ejournals and ebooks are beyond the scope of HKALL.

Due to limited learning space in Hong Kong, seven out of eight member libraries restrict entrance access to their own eligible staff and students only. JULAC Cards are issued to facilitate legitimate users from a home library to physically visit other member libraries to borrow their books or use their collections on site.

There are two categories of JULAC Card: borrower card and reader card. All full-time faculty, academic and equivalent administrative staff, research staff and postgraduate students are eligible to apply for borrower cards at no cost. Reader cards are issued to UGC-funded undergraduate students of all years at a charge. Host libraries will charge HK\$50 (US\$6.4) for a new registration or upon renewal.

The original JULAC Card was designed in 1991. The entire process of application, card production and registration was paper-based. When a JULAC Card holder accessed a host library for first-time registration, he/she was required to bring a photocopy of the original JULAC Card application form. The library staff of the host library had to manually enter the patron information into the library's circulation system, issued a barcode sticker and attached it to the card for entrance identification and book borrowing.

The JULAC Card was a twice-folded paper card for accommodating seven barcodes. As lamination was not allowed, the paper cards could easily wear out [Figure 1]. Very often, users forgot to bring photocopies of application forms for registration purpose and had to be turned away by the host libraries. Further complications occurred when two member libraries started issuing separate smart cards for JULAC Card holders. A possible scenario was that a user had to keep three cards for accessing all host libraries. 
1. The holder of this card is hereby granted permission to use all the libraries of Joint University Librarians Advisory Committec (JULAC).

2. The holder of this card agrees to observe all regulations and privileges of those libraries visited.

3. This card is not transferable.

4. This card must be shown along with your institution's card as a proof of identity if requested by Library Staff concerned

5. This card must be returned to the lssuing Library upon termination of service.

Damage or loss of this card must be reported to the Issuing Library as soon as possible

Charge for card replacement will be HK $\$ 50$

Please retain this card for future use if your membership with your institution may be extended further than the expiry date issued on this card.

Back

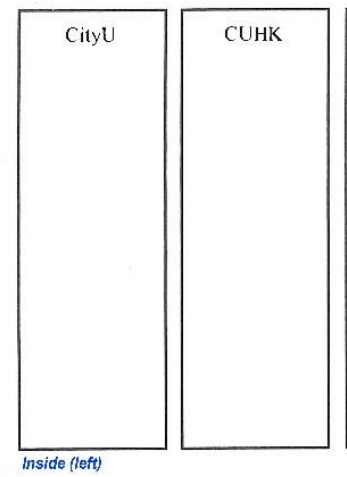

JULAC LIBRARY CARI)

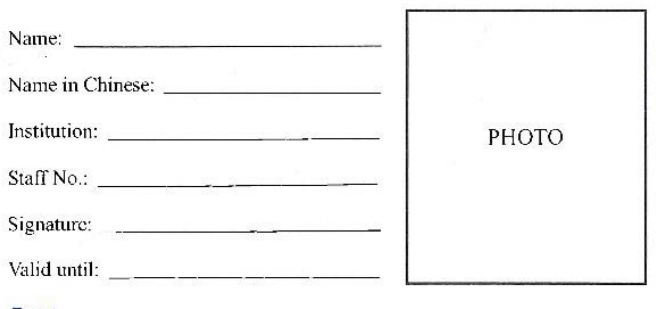

Front
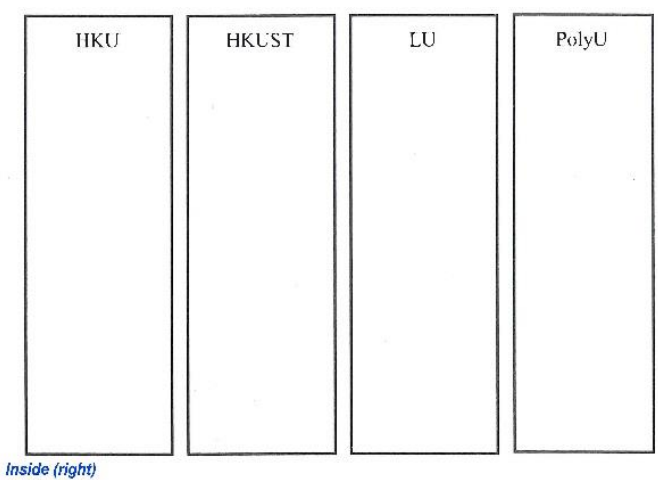

[Figure 1] Old JULAC Card

The old card was inconvenient for users and the manual registration procedure was cumbersome. JASC initiated a project a few years ago to re-design JULAC Card and its workflow. JULAC Systems Committee (JSYS), which was involved in the initial discussions, had grave concerns for data security regarding the storage of patron data and the transfer of data across institutions. In the end, these two JULAC committees officially joined hands. A Task Force for the JULAC Card Project, chaired by the Hong Kong University of Science and Technology (HKUST) Library, comprising eight members from JASC and JSYS, was formed in April 2013. The goals of the Project were to streamline card production and registration processes at host libraries, maximize users' convenience and facilitate cross-institutional resource sharing.

\section{Literature Review}

Resource sharing

Libraries commonly join resource sharing programs in order to enable reciprocal borrowing and lending of books and other returnables among member libraries. A survey with 388 responding libraries of the Southeastern Library Network (SOLINET) reveals that $97.4 \%$ of respondents participated in some types of resource sharing agreements at state or county level (Williams, 2008). 
One notable example is a service called UBorrow which enables users to search for and request books directly from 13 major research libraries in the Midwest and the Center for Research Libraries in the U.S. with a total holding of over 90 million books. Another example is Borrow Direct. It is an unmediated library resource sharing partnership encompassing Ivy Leagues and other libraries supplying over 250,000 library items per year. Borrow Direct also offers on-site borrowing. When a legitimate user shows one's campus ID card and logs into the home library account from a host library, the user will be issued a library card from the host library.

In 2009, a group of Nova Scotia libraries in Canada launched the Borrow Anywhere Return Anywhere (BARA) program which entitles its residents to borrow and return materials in any participating academic, college and public library (van den Hoogen and Parrott, 2012).

\section{Interlibrary loans}

Resource sharing programs can be placed on a cost spectrum, with interlibrary loan, shared consortial catalogs and reciprocal borrowing occupying different spots on the spectrum (Duy and Lariviere, 2013). Interlibrary loan service is most costly as the library has to mediate the loan transaction on behalf of the user. A study on interlibrary loan borrowing costs suggests an average transaction cost was close to US\$10 (Leon \& Kress, 2012).

\section{Shared consortial catalogs}

Libraries from different institutions with a shared consortial catalog enable users to request materials directly through their catalog without going through interlibrary loan mediation. This patron-driven unmediated service is normally processed through the circulation department. The average cost was found to be US\$3.85 in the same study (Leon \& Kress, 2012). In Hong Kong, users search HKALL, the shared consortial catalog, and order materials directly from other JULAC libraries, with an average delivery time of two to three working days. The cost on courier per transaction was around HK\$2.5 (US\$0.32) in 2014/15.

\section{Reciprocal borrowing}

Reciprocal borrowing is an arrangement among libraries that allows registered patrons to borrow materials from all member libraries. It is the cheapest method as minimal library staff time is involved. Users can use existing library cards or are given separate cards to borrow from host libraries. In a 2004 state-wide survey conducted by the American Library Association's Office for Research and Statistics on the presence of reciprocal borrowing, 50\% of the respondents reported state-wide reciprocal borrowing among all library types, and $27 \%$ reported reciprocal borrowing among public libraries only. Responses regarding multi-state reciprocal borrowing were 33\% positive and 33\% negative. Another 31\% reported they were not aware of such arrangements (Davis, 2005). 
The CAVAL Reciprocal Borrowing Program enables students and staff to borrow from the print collections of 80 participating libraries of universities and colleges in Australia. After a user registers in this program, he/she will be given a CAVAL card. If the user needs to borrow direct from another library, he/she needs to present a CAVAL card together with the home library ID card. The host library will attach a barcode label to the CAVAL card.

A 1993 study reveals that the top two reasons for patrons to use reciprocal borrowing are the perceived quality of library collections and geographic proximity (Kies, 1993). A recent study reaffirms the above two factors, despite a lapse of twenty years (Duy and Lariviere, 2013).

\section{One Card}

In enabling reciprocal borrowing, many academic and public libraries adopt a one library card scheme.

Pennsylvania introduced a state-wide library card system in the late 1980s, providing all citizens full access to the holdings of 162 publicly supported school and academic libraries of the commonwealth (Library Journal, 1985). The number of participating libraries increased to over 2,600 in 2013 (http://www.accesspa.state.pa.us/).

Edmonton Public Library launched Me Card in October 2013. After a user registers, a user account in the integrated library system of a host library will be created. The new account requires no involvement from library staff and no additional library card. The Me Card does not require a shared integrated library system among participating libraries. It allows users to access over 10 million items from over 300 participating libraries in Alberta for free (ALA, 2014). Academic library users may also register for accessing and checking out materials from any Edmonton Public Library.

One Card library system is popular in China too (Lin, 2002). One Card allows registered users to access and borrow library materials in the Capital Library Alliance of 110 academic and public libraries in Beijing (http://www.clcn.net.cn/special/cla/) (http://www.bplisn.net.cn/regcard.aspx). One Card spreads to many cities including Shanghai, Chengdu, Chongqing, Dalian, Taipei, Taichung, among others.

\section{Proposed New Model}

Some Hong Kong JULAC libraries adopted local practices to enhance their internal paper JULAC Card processing and workflow (So and Ho, 2010). Yet there was no effective and systematic solution to achieve full automation covering card application, card production and on-site registration on a consortial basis. 
In designing a solution to benefit all institutions, several major issues had to be resolved. Patron data transfer across institutions was one key concern. Although all member libraries had adopted the same integrated library system since 1997 (Hong Kong University of Science and Technology Library, 2006), there were a number of technical considerations about establishing a mechanism to share patron records. First, according to the personal data privacy law in Hong Kong, the personal information stored in the system of one institution cannot be shared with other institutions unless prior consent of the patrons is sought (Office of the Privacy Commissioner for Personal Data, Hong Kong, 2015). Thus, a model of establishing a central JULAC patron database was not feasible. Second, even though member libraries used the same integrated library system, their requirements of patron record fields varied. For instance, some libraries used Hong Kong Identity Card (HKID Card) number as one of the key indexed fields to identify their patrons whereas some libraries did not keep HKID Card number in their patron records. Third, the patterns of patron barcodes among institutions were not standardized, and in many cases they even had contradictions. These technical problems made the sharing of patron information among institutions difficult and explained why the paper JULAC Cards had been used for so many years.

\section{Plastic card with a common barcode pattern}

The Task Force adopted JSYS's recommendation of making a new plastic JULAC card with a printed barcode. The challenge of this design was to search for a common barcode pattern that would not conflict with the patron barcode sequences that were in use in all member libraries. After numerous rounds of trial and enhancement, a common barcode pattern was established [Figure 2].

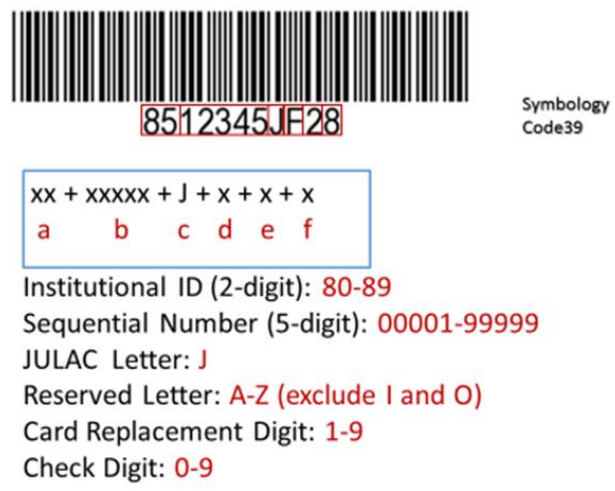

[Figure 2] JULAC Common Barcode Pattern 
The common barcode design enables member libraries to swap from paper to plastic card production as only one barcode is needed and issued by the home library. It can also speed up the production process. Labor intensive work, such as typing the patron information on paper cards, cutting and attaching patrons' photographs, and completing application forms, is eliminated. Additionally, the new design facilitates a One Card system for accessing and borrowing across member libraries. The inept situation of having three cards for accessing seven host libraries will disappear.

\section{JULAC Card Registration System}

The new proposed system infrastructure must allow member libraries to create and store patron data in a commonly agreed format and pattern. It also needs to establish a new standard and mechanism for transferring and sharing patron record data among libraries in a fully automated environment.

After a few rounds of investigation, it was decided to adopt a "patron-record-on-demand model" for the new registration system. It is based on the principle that the transfer of patron data will only occur when the card holder of one home library is performing registration at a host library, and that the transfer will only be triggered by the card holder. This system also facilitates card holders to input the host library's mandatory fields (e.g. HKID Card number) which are not captured in the original patron records transferred by their home library. With this model, the statutory requirements on personal data privacy will not be compromised. The variation of patron record field issues discussed above can be resolved (Lam and Li, 2013).

A JULAC Card Registration System was designed to implement this model. This system authenticates a card holder's identity on the spot via the home library's authentication system.

Once verified, the registration sub-system residing at the home library will retrieve the patron data from its own integrated library system and display it on the web browser so that card holder can verify and input additional data. Then, by clicking the submit button, the card holder approves and initiates the transfer of his/her own patron data to the registration sub-system of the host library for subsequent updating to its integrated library system and gate control system.

With the new registration process, a card holder is no longer required to bring a photocopy of the application form to the host library for registration. Instead, patron data is automatically transferred and updated to the affected systems, all under the direct control of the card holder and it occurs only during onsite registration.

\section{Implementation}

The responsibilities of the Task Force were varied: drafting specifications; tendering card printers and printing software; determining card design; contacting integrated library system vendor to 
accept a new barcode pattern; testing the electronic turnstile systems at different institutions; and smoothening the logistics and registration models at the host libraries. JASC focused on launching the new JULAC Cards at individual and consortia level. JSYS was engaged with programming and providing technical support.

\section{Card design and card production}

The Task Force drafted a specification document in September 2013. Members of JASC and the Task Force went through a tendering process to select a vendor for the design and supply of plastic pre-print cards, card printers and a software to print the cards for eight libraries. They shortlisted potential tenderers, interviewed the vendors and selected the supplier. HKUST oversaw the tendering process and awarded the contract to a company on behalf of JULAC libraries in late November 2013. Several technical meetings with the awarded vendor were conducted from December 2013 to January 2014. After getting the finalized card design [Figure 4] in February 2014, over 50,000 pre-print cards and eight printers with customized printing software were delivered to member libraries in April that year. User acceptance test was performed at each institution.
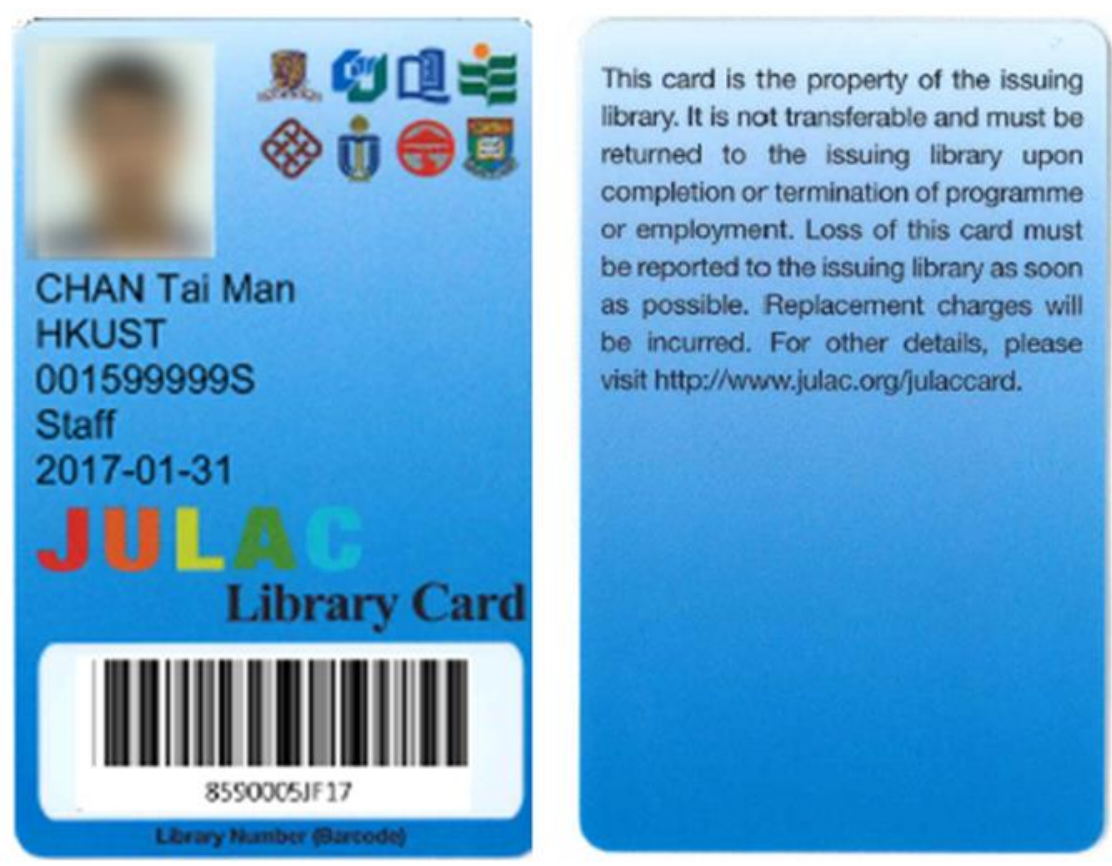

[Figure 3] New JULAC Card

\section{Programming}

In addition to the common card printing system, JSYS designed the new registration system and HKUST developed its core programs. Each member library developed a local module to 
authenticate their own users, validate eligibility, and retrieve patron data from their integrated library systems. Another local module was also developed by member libraries for online import of patron data into their own integrated library systems. A testing session on the beta version of the system was conducted in mid-March, 2014 to identify access problems. Circulation and systems colleagues of each institution were involved. All member libraries received user training. The schedule of releasing the system was aligned with the launch of the card printing solution. Systems colleagues of each institution were able to complete their local modules in time to meet the launch date target.

\section{Timeline}

The new JULAC Card was launched on May 19, 2014 when members' black-out periods ${ }^{3}$ were over. A JULAC Card webpage (http://www.julac.org/?page_id=3614) was rolled out. There was a transitional period which allowed the coexistence of the new and the old cards. The old cards were to be phased out by the end of 2014.

\section{Review}

\section{Statistics}

From May 2014 to June 2015, 3,664 new cards were issued as card replacement, with an overall replacement rate of $62.63 \%$. [Table 2]

\begin{tabular}{|l|c|c|c|}
\hline JULAC Member Libraries & $\begin{array}{l}\text { Paper Card to be } \\
\text { replaced (expired } \\
\text { after Dec 31 2014) }\end{array}$ & $\begin{array}{l}\text { New JULAC Card } \\
\text { issued for replacing } \\
\text { paper card }\end{array}$ & Replacement rate \\
\hline City University of Hong Kong & 923 & 579 & $62.73 \%$ \\
\hline The Chinese University of Hong Kong & 1435 & 966 & $67.32 \%$ \\
\hline Hong Kong Baptist University & 569 & 393 & $69.07 \%$ \\
\hline The Hong Kong Institute of Education & 242 & 201 & $83.06 \%$ \\
\hline The Hong Kong Polytechnic University & 990 & 485 & $48.99 \%$ \\
\hline Hong Kong University of Science and Technology & 290 & 240 & $82.76 \%$ \\
\hline Lingnan University & 268 & 184 & $68.66 \%$ \\
\hline University of Hong Kong & 1133 & 616 & $54.37 \%$ \\
\hline Total & $\mathbf{5 8 5 0}$ & $\mathbf{3 6 6 4}$ & $\mathbf{6 2 . 6 3 \%}$ \\
\hline
\end{tabular}

[Table 2] Replacement for New JULAC Card (May 2014 - June 2015)

\footnotetext{
${ }^{3}$ Due to limited study space, some member libraries implement limited access periods (blackout periods) during which access by JULAC Card holders is prohibited. Blackout periods usually coincide with examination time.
} 
Heavy promotion campaigns raised users' awareness of JULAC Cards, eliciting many new applications. A total of 6,388 new cards were issued from July 2013 to June 2014 whereas 9,187 new cards were issued (excluding cards issued for replacement) from July 2014 to June 2015. The increase rate was a solid $43.03 \%$. The increase showed in all categories of users, i.e. $5.24 \%$ for faculty and staff; $48.43 \%$ for postgraduates and $41.70 \%$ for undergraduates. [Figure 4 ].

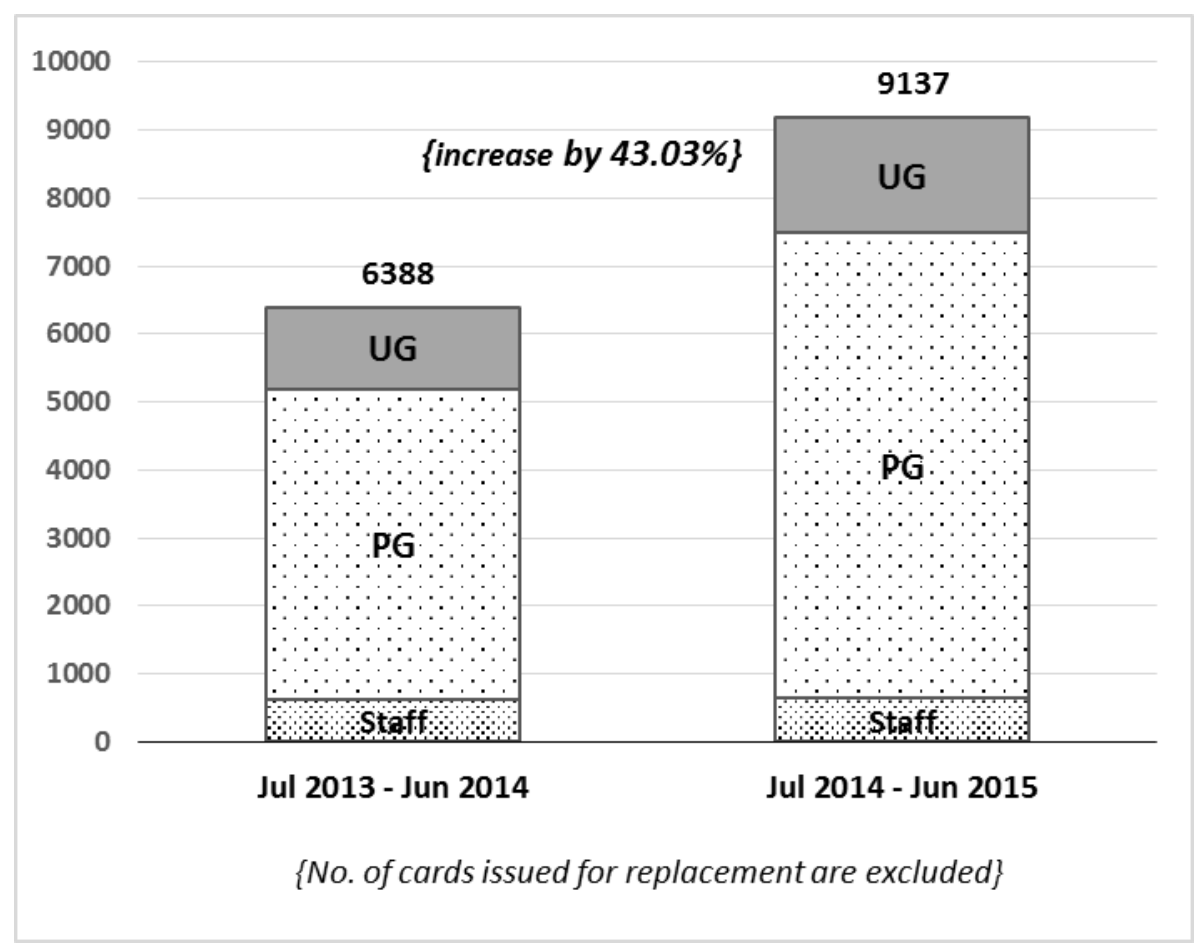

[Figure 4] [New JULAC Card Application]

From July 2014 to June 2015, the total number of users entering JULAC libraries decreased 3.32\% whereas the total number of JULAC Card holders accessing host libraries increased $8.25 \%$. This suggests that the new card system encourages JULAC users' physical visits to host libraries and enables greater cross-institutional use of library resources.

\section{Provision of service}

The new card system maximizes users' convenience. Plastic cards are durable. The registration process has been streamlined. Users no longer need to bring photocopies of application forms to host libraries for registration. The processing time is short. A user only spends one minute on registration and can borrow books the next minute.

\section{Administration}

The new card system improves staff efficiency. Due to automated card production and registration process, manual and tedious workflow become a thing of the past. 


\section{Challenges}

Technical

Many technical issues were involved in this project. The card with a common barcode has to be accepted by the entrance gates of all member libraries and their branches. The card has to allow users to borrow items from all member libraries. In designing the card, there were intense discussions on whether to include the expiry date of users' program or employment. This date will help late evening security guards to verify users' status if necessary. Yet, adding the expiry date will no doubt increase the printing frequency when the employment contracts or academic programs are extended. Weighing the pros and cons, the consensus was to include the expiry date on the new card. For undergraduates, it is the end date of each academic year, i.e. July 31 . For postgraduates and contract staff, it was agreed to adopt the same expiry date as recorded in their home library. For tenured staff, different universities adopt different formats, such as "__ “ or "2037". All these variations are allowed and documented.

One JULAC library does not accept barcodes but uses Mifare for entrance gate access control and record retrieval from their integrated library system. This library has to issue a Mifare tag to be applied on the back of the new JULAC Card. A small area is reserved at the back of the card for this purpose.

Several institutions used online forms to handle JULAC Card applications while some still relied on manual forms. Through this project, those with manual forms eventually migrated to online forms.

\section{Leadership}

This common card concept had been on the agenda of JASC for many years. Proposals were put forward and considered, but none could move forward. The key to success was the deep collaboration of JASC and JSYS. The Task Force formed by members of both committees brought concerned parties to the same table to brainstorm, debate and reconcile differences. All decisions and recommendations were brought back to the two committees for verification and revision. Without a strong determination to collaborate and succeed, the project would not have come to fruition.

\section{Implementation}

An implementation timeline was laid out so that the promotion to replace the paper card with the new card started in May 2014. From May to December 2014, both paper cards and plastic cards were in parallel use. By January 2015, all institutions were requested to retire their paper cards. There were concerns that eligible users were not allowed to enter host libraries because they had not changed their cards in time. It was agreed that users with paper cards were still allowed to enter, but their names were recorded and they were reminded to have their cards replaced. Old 
patron records will be kept for 18 months from January 2015 for verification purposes. Individual libraries can decide if they allow checkouts using paper cards.

\section{Management Discussions}

In the spirit of deep collaboration, each institution took up different responsibilities, although some institutions were assigned a bigger slice than the others. One institution designed the card layout, another wrote the specifications and organized the sharing session, and the third library developed the core programs to retrieve and share patron data as well as coordinated the tender.

The benefits of the project are two-fold. For users, they enjoy much improved services and greater convenience. They need not present photocopies of the application forms for registration at host libraries. Registration process is shortened from ten to one minute. They can borrow books immediately after registration. For staff, they can save time and efforts as the workflow has been streamlined and automated. The card production process is fast and efficient. The card registration process is simplified and shortened.

The project's success is a result of intense discussions, hard work, and an uphill journey of compromise and adjustment. All concerned parties learnt a good lesson in resolving conflicts caused by internal policies, local practices and workflow of individual libraries.

The number of new JULAC Cards issued was high, yet the physical access of JULAC Card holders to host libraries only increased $8.25 \%$ from July 2014 to June 2015. This small gain is significant and should be viewed within the context that the total number of users entering JULAC libraries decreased $3.32 \%$ in the same period. Demand on print materials has been declining. HKALL statistics show this downward trend in the last few years.

JULAC Card is a reciprocal borrowing arrangement enabling users to access, browse and borrow items from host libraries. It is still not a One Card solution in which students use their institutional ID cards to access other host libraries. Other countries or regions offer One Card solution, but Hong Kong cannot follow suit since most academic libraries have access control at their entrance gates which ties in with their institutional IDs. JULAC libraries do not attempt to unify different institutional ID cards which will involve huge efforts with no guaranteed outcome.

JULAC libraries are moving towards a shared integrated library system. The system, running on a single instance of software for all JULAC libraries and capable of sharing of database records, is expected to foster wider and deeper collaboration among institutions. The JULAC Card Registration System may be modified in due course after the shared integrated library system is fully implemented. 


\section{References}

ALA Office for Information Technology Policy. (2014), “Cutting-edge technology for library services", available at:

http://www.ala.org/offices/sites/ala.org.offices/files/content/oitp/cuttingedge/ala_cutting_e dge6-10-2014b.pdf (accessed Oct 2, 2015)

Davis, D. (2005), “Reciprocal borrowing arrangements widespread", American Libraries, Vol. 36 Iss. 1, pp.26.

Duy, J.C. and Lariviere, V. (2013), “An analysis of direct reciprocal borrowing among Quebec university libraries”, Journal of Access Services, Vol.10, pp.102-119.

Hong Kong University of Science and Technology Library (2006), $7^{\text {th }}$ Annual Hong Kong Innovative Users Group Meeting Program and $10^{\text {th }}$ Anniversary Commemoration, available at: http://hkiug.ln.edu.hk/meetings/am2006/, (accessed April 21, 2015)

Kies, C. (1993), "Patron rationales for using reciprocal borrowing", Resources Sharing \& Information Networks, Vol. 9 No. 1, pp.11-32.

Lam, K. T. and Li, Y. O. (2013), "JULAC Common Card Project", JULAC Libraries Forum, Hong Kong Baptist University Library, November 29, 2013, available at: http://hdl.handle.net/1783.1/8039, (accessed April 21, 2015).

Leon, L. and Kress, N. (2012), "Looking and resources sharing costs", Interlending \& Document Supply, Vol. 40 No. 2 pp. 81-87.

Lin, W. (2002), “All in one card - the new field of library automation”, available at http://www.cnki.net (accessed September 20, 2015).

Office of the Privacy Commissioner for Personal Data, Hong Kong (2015), "Data Privacy Law Ordinance at a glance", available at:

http://www.pcpd.org.hk/english/data_privacy_law/ordinance_at_a_Glance/ordinance.html (accessed April 21, 2015).

"Pennsylvania launches pilot of statewide library cards", Library Journal, Vol. 110 No. 20, p.32, December 1985.

Perushek, D. E. and Douglas, A. (2014), "Culture, politics and university library consortia in China and the US: A comparative introduction to CALIS, GWLA and JULAC", Library Management, Vol. 35 Iss. 8/9, pp.594-606.

Sidorko, P., Wong, R., Tai, A. and Wong, E. (2006), "User-initiated resource sharing in Hong Kong universities: planning to reality with HKALL", Interlending \& Document Supply, Vol. 34 Iss. 2, pp.60-69. 
So, E. and Ho, W. (2010), "Inter-library access solution in Hong Kong academic libraries", Interlending \& Document Supply, Vol. 38 Iss. 4, pp.237-244.

van den Hoogen, S. and Parrott, D. (2012), "Communication, collaboration and cooperation: an evaluation of Nova Scotia's Borrow Anywhere, Return Anywhere (BARA) multi-type library initiative", The Journal of Academic Librarianship, Vol. 38 No. 6, pp.321-325.

Williams, K.C. (2008), "Consortial and reciprocal agreements in academic libraries: a survey of common practices", Journal of Interlibrary Loan, Document Delivery \& Electronic Reserve, Vol.18 No.2, pp.265-278. 